\title{
- Smart Local Energy Systems (SLES): 2 A framework for exploring transition, 3 context, and impacts
}

4

\author{
Brief running title: Smart Local Energy System Framework \\ Rebecca Ford ${ }^{1,{ }^{*}}$, Chris Maidment ${ }^{2}$, Carol Vigurs $^{3}$, Michael J. Fell ${ }^{2}$, Madeleine Morris ${ }^{4}$ \\ ${ }^{1}$ University of Strathclyde, 16 Richmond St, Glasgow G1 1XQ (rebecca.ford@strath.ac.uk) \\ * Corresponding author \\ ${ }^{2}$ UCL Energy Institute, University College London, Gower Street, London, WC1E 6BT, \\ United Kingdom (c.maidment@ucl.ac.uk; michael.fell@ucl.ac.uk) \\ ${ }^{3}$ UCL Institute of Education, University College London, 20 Bedford Way, London, WC1H \\ OAL, United Kingdom (c.vigurs@ucl.ac.uk) \\ ${ }^{4}$ Grantham Institute, Imperial College London, South Kensington Campus, London SW7 \\ 2AZ, United Kingdom (m.morris13@imperial.ac.uk)
}

\section{Abstract}

Energy systems globally are becoming increasingly decentralised; experiencing new types of loads; incorporating digital or "smart" technologies; and seeing the demand side engage in new ways. These changes impact on the management and regulation of future energy systems and question how they will support a socially equitable, acceptable, net-zero transition. This paper couples a meta-narrative literature review with expert interviews to explore how socio-technical regimes associated with centralised systems of provision (i.e. the prevailing paradigm in many countries around the world) differ to those of smart local energy systems (SLES). Findings show how SLES regimes incorporate niche technologies, business models and governance structures to enable new forms of localised operation and optimisation (e.g. automated network management), smarter decision making and planning, by new actors (e.g. local authorities, other local stakeholders), and engaging users in new ways. Through this they are expected to deliver on a wide range of outcomes, both within the SLES boundary and to the wider system. However, there may be trade-offs between outcomes due to pressures for change originating from competing actors (e.g. landscape vs. incumbents in the regime); understanding the mapping between different outcomes, SLES elements and their interconnections will be key to unlocking wider benefits. 


\section{Keywords}

2 Smart local energy systems; Decentralised energy; Energy democratisation; Smart cities;

3 Community energy; Energy transition; Meta-narrative review; Expert interviews

\section{Abbreviations}

5 DNO - Distribution Network Operator

6 DSO - Distribution System Operator

7 SLES - Smart Local Energy System

\section{Funding Sources}

9 This work was supported by UK Research and Innovation Grant No EP/S031863/1 "Energy 10 Revolution Research Consortium - Core - EnergyREV", administered by the Engineering 11 and Physical Sciences Research Council (EPSRC). 


\section{Introduction}

2 Energy systems around the world are changing in response to global challenges and targets

3 to limit climate change. They are becoming increasingly reliant on decentralised renewable

4 or low carbon generation resources, experiencing new types of loads such as electric

5 vehicles, heat pumps, and storage, incorporating digital or "smart" technologies, and seeing

6 the demand side engage in new ways [1,2]. These changes impact on how energy systems

7 are designed, developed, managed, and regulated. They also raise questions around how

8 emerging energy system transitions can ensure a socially equitable and just transition [3, 4].

9 Understanding emerging energy system transitions in terms of the sorts of benefits they may

10 deliver, the implications on social and technological system elements, and the sociotechnical pathways through which change occurs is essential to ensure that policy makers, investors and the wider industry are able to plan for, develop, and deliver a net-zero and socially equitable and acceptable future.

Current practices of energy system planning and management are based on traditional paradigms of centralised generation and top-down system operation. However, the increasing prevalence of decentralised generation is driving a shift toward more localised scales of energy provision and management practices. In the UK this is exemplified by the ongoing DNO-DSO transition, encouraging more active management on distribution networks and the provision of ancillary services at increasingly localised levels ${ }^{1}$. It is further illustrated in the upsurge of microgrids around the world, often focussed on delivering increased reliability, resilience, and security of supply [5], and the increasing interest and business models and markets around peer-to-peer energy services, which allow end users to become more active energy system participants [6].

The decentralised nature of renewable energy has also seen the emergence of new types of stakeholders, including community groups and grassroots organisations, local authorities, and local enterprise partnerships working alongside private sector businesses [7]. The diversification from traditional system actors introduces new goals and values around what local energy systems could (or should) be delivering in addition to traditional energy services. This includes meeting local social, economic and environmental needs, contributing to broader environmental challenges, delivering economic growth and prosperity, creating jobs and providing new skills training [7].

Aligned with these changes is a push toward digitalisation [8-10], exemplified by the introduction of smart meters, greater prevalence of "Internet of Things" devices in homes and businesses, and increasing sophistication of automation (e.g., artificial intelligence) used to provide system services. This "smartness" provided by digitisation is driving exponential growth in the scale and diversity of data available to system actors, presenting opportunities and challenges in equal measure [11].

In the UK there has been a plethora of demonstration projects, incorporating both traditional and emerging energy system actors, to explore the challenges and opportunities associated with a shift toward low carbon, smart, local energy system development and delivery [12].

\footnotetext{
${ }_{1}^{1}$ For further information, see the Energy Networks Association Open Networks Project http://www.energynetworks.org/electricity/futures/open-networks-project/
} 
Such demonstration projects are critical to support innovation, however most focus on delivering technology specific learning, paying little attention to the wider societal or policy

that they are helping to deliver [12, 13].

This paper presents findings from a meta-narrative literature review, coupled with interviews focussed on the conceptualisations of smart local energy systems, and explores the sociotechnical transition emerging through increasing energy system digitalisation and decentralisation. It aims to assist those planning, implementing or regulating smart local energy systems understand more precisely how projects are 'smart' or 'local', what this means in terms of technological or social change, and how this might contribute to the delivery of anticipated benefits.

As this paper will show, definitions or descriptions of SLES are not forthcoming in the literature; these systems are generally discussed without being clearly defined (probably due to the relative novelty of the precise concept). However, previous work has explored and defined concepts of "smart energy systems", e.g. [14-18], and "local energy systems", e.g. [19]. This work is drawn on in the current study. While much has also been written about energy systems in general, and particular concepts relating to energy systems (e.g. decarbonisation goals, decentralised energy, community energy, energy democracy and governance, digitalisation and smartness), no work was identified in the current study that explored how these concepts come together to deliver a SLES. Only by exploring the mental and more formal theoretical models by which a smart local energy system transition is conceptualised, can an understanding be formed around how such systems might deliver intended benefits, how they might need to be governed, and what implications this may have for energy sector stakeholders.

\section{Socio-technical energy transitions}

Socio-technical transitions are multi-dimensional processes involving co-evolutionary interactions between technologies, supply chains, infrastructures, firms, markets, user practices, cultural meanings, and institutions [20, 21]. Socio-technical transitions in energy are typically purposive in nature (rather than emerging from opportunistic niche developments), responding to climate change goals and/or delivering wider technical, social, economic, environmental and political benefits [22, 23]. Understanding and analysing energy system transitions therefore requires a broad exploration of these cross-cutting issues, encompassing both the purpose and process of transition.

The multi-level perspective (MLP) provides a useful framework for considering the multidimensional complexity of changes in socio-technical systems [24-28]. The MLP positions socio-technical transitions as the outcome of interactions within and between the incumbent regime, niche-innovations and the exogenous landscape [20,29]. The landscape refers to slow changing trends (e.g. demographics, spatial structures, cultural and normative values, political structures) and shocks (e.g. elections, pandemics) that influence the regime or facilitate the breakthrough of niche innovations, but over which regime actors have little or no influence. 
Niche innovations, or combinations of multiple innovations, include emerging social and/or technical innovations that present radically different ways of doing things compared to the incumbent regime. For example, emerging low carbon energy transitions may incorporate innovations in distributed renewable energy generation technologies, storage technologies, demand side management techniques, new business models (e.g. heat as a service, aggregation), new market arrangements and digital platforms (e.g. peer-to-peer), and new paradigms for system operation resulting from the use of information and communication technologies alongside machine learning and artificial intelligence. These niche innovations may be able to gain traction in particular areas, leading to destabilisation and changes within patchworks of the prevailing socio-technical regime (see Figure 1).

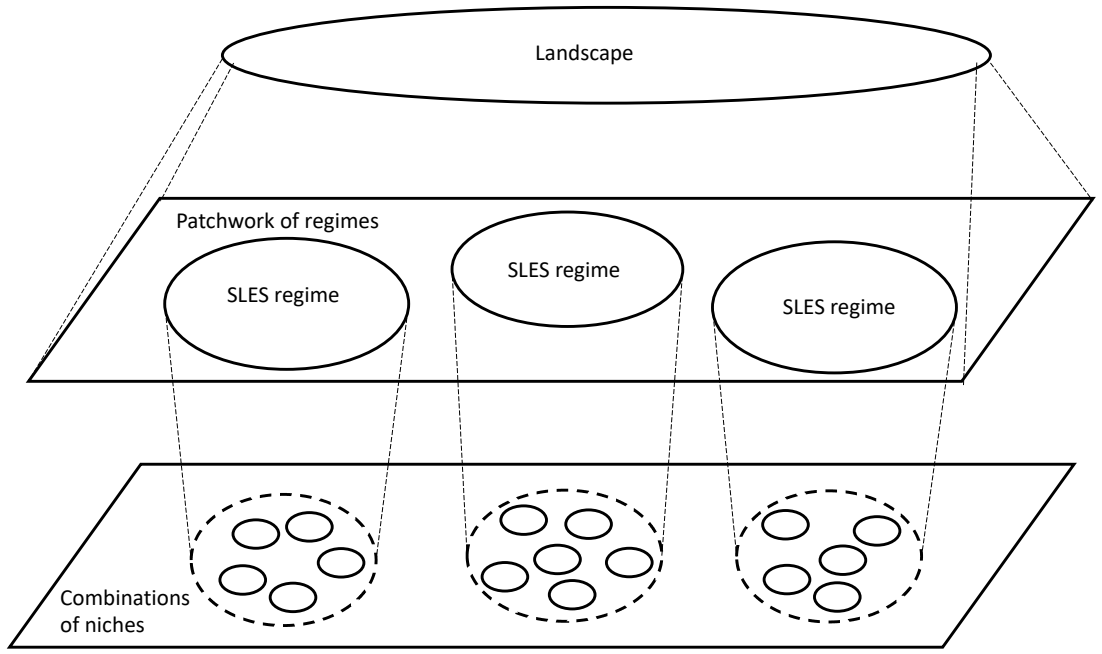

Figure 1: Representation of the multi-level perspective, adapted from [19]

14

The current study explores how socio-technical regimes differ from centralised systems of provision (i.e. the prevailing paradigm in many countries around the world) to decentralised SLES are conceptualised, both in the literature and by experts. It examines how "smart" and "local" are understood in the context of energy systems and explores how SLES regimes might deliver against some underlying purpose (e.g. landscape pressures to reduce carbon emissions in line with national policy) or drive benefits not realised by incumbent arrangements.

\section{Methods}

This study combined a systematic meta-narrative review of conceptualisations of 'smart' and 'local' in the context of energy systems, with expert interviews from a multidisciplinary group of researchers, allowing for direct elicitation of these concepts. This section describes the aims and focus of these two approaches and outlines how findings have been combined.

\subsection{Meta-narrative review}

The meta narrative review is a systematic review approach developed by Greenhalgh and colleagues $[30,31]$ to delineate varying and overlapping "storylines" of a given topic by diverse disciplines and research traditions over time. As a review method, it is suited to 
gaining understanding of contested concepts, differing perspectives and conflicting findings.

2 This meta narrative review follows the RAMESES (Realist And Meta-narrative Evidence

3 Syntheses: Evolving Standards) publication standards [32] for meta-narrative reviews.

\section{$4 \quad 3.1 .1$ Search strategy}

5 In the initial stages of the review, relevant papers were identified from pilot searches for

6 literature with usages of key terms such as "smart energy system" and "local energy

7 system". Recommendations were also invited from colleagues in the EnergyREV

8 consortium, of which this study is a part.

9

10

A wider systematic search strategy (detailed in the appendix) was developed from this pilot search and applied in bibliographic databases for academic literature and organisational websites for grey literature, according to the terms, inclusion/exclusion criteria and sources outlined below. The search strategy was an iterative process, as understandings of smart, local, energy systems concepts developed from the literature. Titles and abstracts of the documents, and, where necessary, full papers, were screened for relevance against the inclusion/exclusion criteria. Screening was undertaken by two coders and, while blind double-coding was not employed, the coders conferred extensively early in the process to ensure that criteria were being interpreted in the same way.

\subsubsection{Inclusion and exclusion criteria}

Studies were assessed for inclusion based on the following criteria:

- Inclusion of substantive consideration/discussion of the meaning of smart/local in context of energy systems

- Description of a project or characteristics of energy system projects that are referred to as being smart/local

Inclusion and exclusion criteria were applied to titles and abstracts, and full papers obtained for studies where abstracts suggested they might meet the inclusion criteria. Where title and abstract were insufficient, full papers were obtained, and inclusion and exclusion criteria reapplied. Those not meeting these criteria were excluded. The search strategy was iterative, as a wider understanding of these concepts developed from the literature. All studies meeting the criteria were entered into the EPPI-Centre systematic EPPI-Reviewer software [33].

Studies were not included in or excluded from the literature review for geographical reasons. However, as the terminology "smart local energy system" has evolved from a UK Government funded programme ${ }^{2}$, our searches naturally identified a significant amount of UK literature, with much of the remaining evidence coming from countries that use similar terminology and approaches (predominantly Europe and North America).

\footnotetext{
${ }^{2}$ https://www.gov.uk/government/news/prospering-from-the-energy-revolution-fullprogramme-details
} 
Screening of the results of the searches was undertaken by two coders and, while blind double-coding was not employed, the coders conferred extensively early in the process to ensure that criteria were being interpreted in the same way.

\section{$4 \quad 3.2$ Expert interviews}

5 In addition to the literature, the review integrated stakeholder views drawn from a parallel 6 qualitative study investigating how SLES are conceptualised by those researching them.

7 Expert interviews were conducted with thirteen UK based academics researching a wide 8 range of topics relevant or related to smart local energy system transition.

Participants were recruited to ensure coverage of social and technical dimensions of energy system transition (see Table 1). Their geographical areas of research / expertise include UK, Europe, US, South America, India, Asia, UAE, Africa, Indonesia, Philippines, China, Hong Kong, and Australia.

Table 1: Characteristics of respondents

\begin{tabular}{|l|l|l|}
\hline Participant ID & Gender & Disciplinary background \\
\hline INT1 & $\mathrm{M}$ & Chemistry \\
\hline INT2 & $\mathrm{F}$ & Computer science \\
\hline INT3 & $\mathrm{M}$ & Architecture \\
\hline INT4 & $\mathrm{F}$ & Sociology \\
\hline INT5 & $\mathrm{M}$ & Engineering \\
\hline INT6 & $\mathrm{M}$ & Engineering \\
\hline INT7 & $\mathrm{F}$ & Engineering \\
\hline INT8 & $\mathrm{M}$ & Policy \\
\hline INT9 & $\mathrm{F}$ & Computer science \\
\hline INT10 & $\mathrm{M}$ & Architecture \\
\hline INT11 & $\mathrm{M}$ & Human Geography \\
\hline INT12 & $\mathrm{F}$ & Environmental science \\
\hline INT13 & $\mathrm{M}$ & Engineering \\
\hline
\end{tabular}

Interviews were semi-structured, lasting between 45-60 minutes, and balancing a standardised set of questions with the flexibility to dive into topics as appropriate. Interviews were designed to elicit information related to interviewee's perceptions of SLES. Examples of questions include:

- What do you think about when you hear the term 'smart local energy system'?

- How do you draw a boundary around a 'local' energy system?

- How is 'local energy' different from 'community energy'?

- What do you mean by 'smart'?

An interpretive paradigm [34] was adopted to ensure the diversity of interviewee perspectives were appropriately understood. During each interview the interviewer reflected back interviewee's answers, to ensure subsequent coding of the data and analysis was not overly biased by the interviewer's personal opinions.

The interviews were transcribed verbatim and uploaded into EPPI reviewer 4 [33] as item records. Texts were read and re-read by two reviewers to familiarise themselves with the scripts, and then inductively coded in the same way as the review material. 


\subsection{Integration and analysis}

In the first stage (stage 1), the reviewers familiarised themselves with the texts reading and rereading the studies taking initial notes that could inform the data extraction or if additional searches were necessary for differently defined concepts. Included studies (stage 2) were coded according to descriptive categorisations (e.g., geographical location, keywords, study aims and line by line coding of statements). In addition to these categorisations, the text was inductively coded to capture concepts relating to the characteristics and functions that authors attributed to smart and/or local energy systems (while also recording any explicit definitions provided) collating into patterns or potential themes (stage 3). As new codes were added the reviewers re-read the previously coded studies to see if the new code should be applied elsewhere (stage 4). Text assigned to any code was checked for the consistency of its interpretation and if any further sub codes were needed (i.e. axial coding in Grounded theory methodology [35]). When no new themes were added (saturation), the descriptive coding system was considered complete. In this stage the descriptive codes stay relatively close to the original texts.

The next phase (stage 5) moves from the descriptions and the ordering of concepts and onto a more interpretive stage, in which reviewers looked for interpretive constructs and meanings. The themes were then checked and refined by both reviewers for patterns and similarities until agreement was reached, and these patterns were grouped and named into families of related meanings. The thematic structure was derived empirically from the data, guided by and grounded in prior work on socio-technical energy transitions, primarily through the lens of the multi-level perspective. The importance of each theme was driven by how well these themes enlighten understanding of the concepts rather than prevalence. The final stage (stage 6 ) is presented in the findings of the themes in the rest of this report.

\section{Findings}

Fifty-one relevant sources of information were included; 13 interview transcripts (labelled INT1 to INT13) and 38 sources from the literature review; see references [14-16, 36-68]. A flow diagram of the review process and results is included in the appendix. Most literature sources were journal articles (19) or "grey literature" reports published anywhere (13). Almost all studies were published in the last 10 years, most from a technical perspective (21) followed by policy (13). Analysis of keywords describing the studies identified topics including; Energy system management; Energy generation; Energy futures and transitions; Technologies; Scale and place, and; Study methods including modelling and simulation (see appendix for further details).

Coding structures were developed separately for the interview transcripts and literature review. These were then compared and discussed by the reviewers to produce a combined coding set. This coding was then used to analyse the data and identify the themes emerging from both the interviews and literature (Figure 2). 


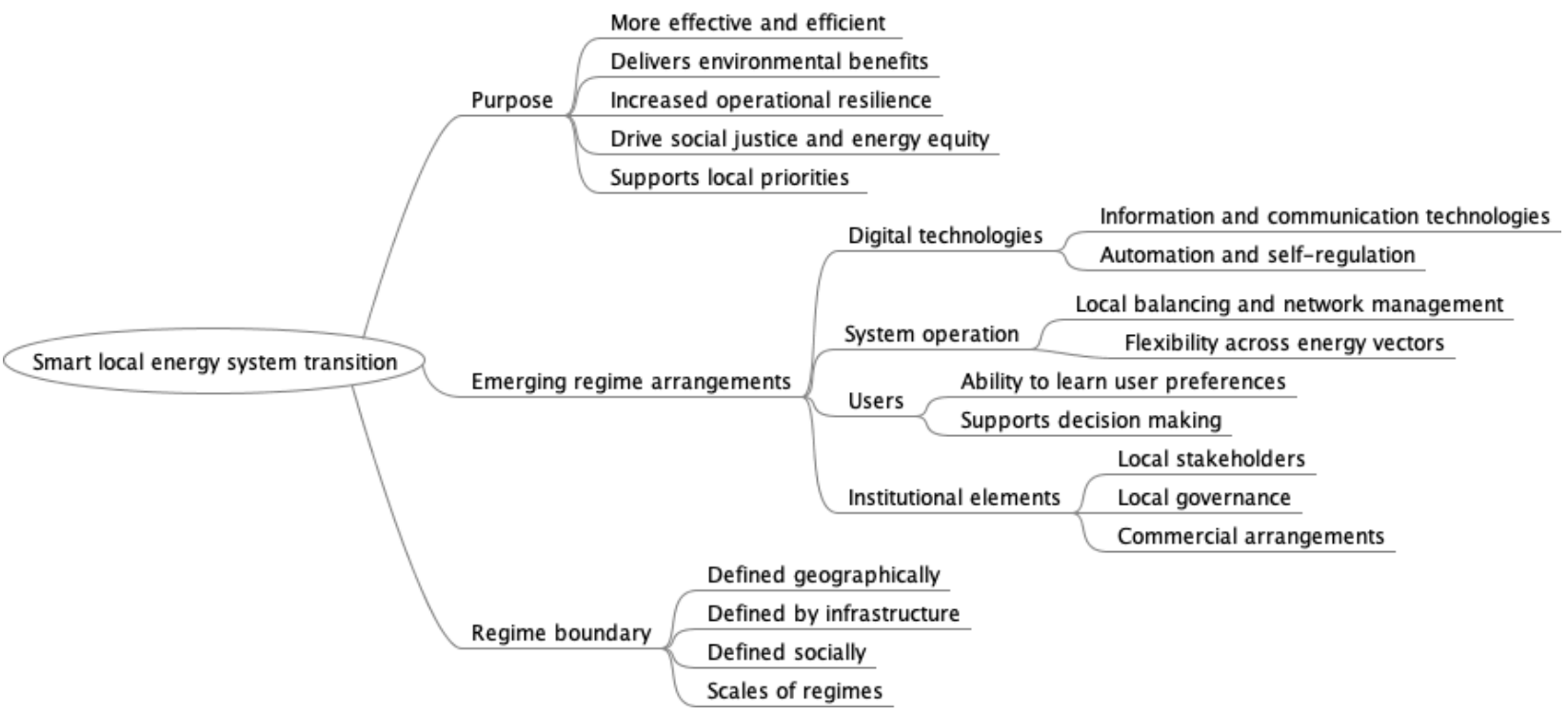

Figure 2: Analytical themes emerging from coding of studies and interview transcripts

\section{$3 \quad 4.1$ Purpose}

Given the purposive nature of energy transitions, this section considers the drivers, functions and goals of implementing a SLES and explores themes related to the efficiency, environmental, operational, and societal benefits that smart local energy systems can deliver.

\subsubsection{More effective and efficient}

This includes the ability of the system to deliver energy services to users in more effective and efficient ways:

“...energy, like money, is an intermediary good in the economy, it serves no purpose whatsoever other than what we can do with it, so an energy system could be defined purely in terms of the services that that energy system is able to provide." INT10

A more effective energy system could be achieved through integration across energy vectors [51] and across "the actions of all users connected to it" [69] in order to deliver more economic energy services. Leveraging smart technology to enable this flexibility was seen as a key aspect of compensating for large quantities of fluctuating renewable energy resources, helping to improve and optimise energy delivery performance, increase system efficiency, minimise energy delivery costs and system costs, and maximise value to stakeholders [14] [15] [44] [67].

However, one interviewee reflected on the need to consider services beyond energy, and the emerging value of data services as energy systems become "smarter":

"What happens when the value of electricity as a data vector approaches or exceeds its value as an energy vector ... then data can start to create new, consumer value propositions ... if you get large data companies, effectively, cross-subsidising energy because of the profit margin on data, then that could start to drive very curious forms 
of energy behaviour which are not rational, purely from a perspective of how energy should be used." INT10

\subsubsection{Delivers environmental benefits}

A key driving element for energy system transition is in the delivery of a low (or zero) carbon economy, reducing greenhouse gas emissions associated with the energy system through the use of renewable generation sources, and reducing environment impacts to a level "within its assimilative capacity" [44, 49, 70].

Interviewees also noted that energy systems interact with wider environmental ecosystems, and that environmental impacts are not limited to greenhouse gas emissions. They noted that other factors, such as land use for renewables rather than food production, are rarely considered despite potentially larger impacts, and outlined the potential for renewable energy to deliver benefits:

"Transition to renewable energy ... also provides opportunities to embed positive, environmental impact, so instead of just avoiding the bad, can we do it in a way that provides environmental, energy, economic win-win?" INT12

\subsubsection{Improves operational resilience}

This concept was mentioned by interviewees; a SLES should be resilient and "able to cope with failure" for instance through alternative grid connections if renewable generation and storage had both stopped (INT9). This could be facilitated using real-time data to enhanced decision making or provide autonomous control.

"a local energy system might provide better security against grid outages ... [with] some local and automated intelligence that could manage a system disconnected." INT5

This could also improve security of supply [44] and reliability [42, 71], and reduce financially expensive system failures [54] in the wider system.

\subsubsection{Drives social justice and energy equity}

By engaging local and community actors in new ways, more local provision of energy systems and services offer the potential to deliver greater energy equity and benefits to the local community. There was recognition that smart local energy systems could help by making energy more affordable, reducing energy bills, improving comfort and quality of life $[43,47]$. It could also open up energy product choices and opportunities to consumers to participate in market [67], and deliver a fairer energy system [43].

However, there was recognition that this would be dependent on the way in which smart local energy systems are designed and delivered, and on the stakeholders they engage. There were also concerns that the trust and empowerment implied by the term 'local' may be presumptive [39] and that who benefits from local energy systems may not be obvious. For instance, one interviewee described an energy company owned by a local authority but with 
customers nationwide, meaning that the "local authority gets very slightly richer at the expense of other local authorities" (INT1), creating the potential for "winners" and "losers" between localities or communities across the country. As one participant outlined:

"it's not only optimising things locally, but it's also achieving good outcomes across the range of economic, social, environmental outcomes at a system-wide or national scale". INT8

\subsubsection{Supports local priorities and needs}

Some interviewees described a SLES as able to "serve a particular community." (INT1), accounting for local and contextual priorities to meet locally specific needs. These may be:

- practical, e.g. convenient for locals to access and take part in the system [39],

- for the community, e.g. achieving benefits for vulnerable locals, boosting local employment and growth [40], or

- wider, value-based needs, e.g. addressing a local desire to reduce global environmental impacts [41].

\subsection{Emerging smart local energy regimes}

The interviews and literature provided insights into how "smart" and "local" niche elements of energy systems might manifest within pockets of emerging SLES regimes to deliver the range of potential benefits explored in Section 4.1. Common themes across the literature and interviews were identified related to operational shifts (i.e. how the energy system is operated), integration of digital technologies, how users are supported, and what institutional arrangements might look like.

\subsubsection{System operation}

A key defining factor of SLES regimes stems from new ways in which energy systems are managed within local boundaries. The main concepts emerging related to the ability and degree of local balancing within the SLES, as well as the way in which this balancing incorporated multiple energy vectors.

\subsubsection{Local balancing}

Local balancing of supply and demand was discussed as a key function of SLES to "minimize the amount of energy absorbed by the grid, maximizing the local use of energy produced by renewable sources" [59].

There was general agreement that an energy system covers everything from "production, conversion, transmission, distribution, and consumption" [36]. This was considered true for smaller, local, scales, even down to single building energy systems where typical components of such a system include local generation, grid connection, storage devices and customer demand. Most interviewees expressed similar views, describing energy systems as "generation and consumption and the infrastructure that interconnects and manages those" (INT9) and "generation or conversion through the way to demand and use and every step along the chain" (INT12). 
Several interviewees took this concept further, requiring a SLES to consume what it produces:

"In order for it to be a [local energy] system, it has to use whatever it generates" INT9

However, another interviewee expressed scepticism about this concept, especially when considering energy systems "from cradle to grave", given their range of inputs and interactions:

"I don't think it applies to local energy systems because I imagine not many energy systems are, in fact, particularly local in terms of the resources put into it." INT12

Thus, while local balancing is considered a key element of smart local energy systems, there was less clarity on the degree to which the SLES are independent from the wider grid. A completely independent SLES may be less resilient and less able to cope with failure than one which interacts with the wider energy system, contrasting with some of the potential benefits SLES are anticipated to deliver. This is also likely to be context specific, as some areas may be generation rich (and therefore never able to consume all that is produced) while others, such as city centres, are likely to be generation poor. This also raises questions over timescales - do supply and demand need to be balanced within the locality at the micro-second level or across the year? Fully balancing supply and demand within a SLES across all points in time may prove highly costly due to reduced supply and demand diversity requiring greater levels of storage. Therefore, to ensure the SLES can deliver the wide range of benefits outlined in Section 4.1, it is more likely that local balancing is employed to maximise the use of local resources, while not adding costs or constraints due to requirements for complete independence.

\subsubsection{Flexibility across energy vectors}

In addition to local balancing, interviewees discussed smart energy systems as including "integration between those different service areas around transport and heating and electricity" (INT8) and "the capacity to switch between different energy vectors" (INT10), enabling balancing across vectors rather than just within a single vector.

The general consensus among interviewees is that an energy system incorporates more than one energy vector, and the concept of a "smart" in this context mean optimising the delivering of energy services across energy vectors (electricity, heat and transport) rather than treating them separately:

"I think the intelligences of smart comes from looking across energy broadly, that you're not just trying to make best use of electricity in this box and make the best use of gas in that box and you are looking to play across the vectors". INT5

Hvelplund [38] described proposed scenarios for transitioning to renewable energy systems in Denmark, stating that:

"...the smart energy system integration is crucial. The scenarios rely on a holistic smart energy system including the use of: heat storages and district heating with 
CHP plants and large heat pumps, new electricity demands from large heat pumps and electric vehicles as storage options, electrolysers and liquid fuel for the transport sector, enabling storage as liquids as well as the use of gas storage." (pg 18)

"an approach in which smart electricity, thermal and gas grids are combined with storage technologies and coordinated to identify synergies between them in order to achieve an optimal solution for each individual sector as well as for the overall energy system", [51].

Hargreaves et al. [43] also highlight this integration, describing electricity smart grids as "multi-dimensional, linking it to gas and other sources of thermal energy, such as heat from industrial processes and buildings, electrified and hybrid transport systems."

\subsubsection{Integration of digital technologies}

Fundamental to delivering more local and flexible operating paradigms that characterise SLES regimes, are underpinning "smart" technologies driving "digitization, informatization, automation, interaction, intellectualization, accurate measurement, extensive communication, autonomous control and wide compatibility" [16]. Consequently, a smart energy system can be thought of as "a networked and embedded platform for realizing a dynamic energy mix and optimizing the energy consumption dynamically" [72]. The following sections consider how the integration of niche technologies - including information and communication technologies and automation and self regelation - into the energy system characterises the operation of SLES regimes.

\subsubsection{Information and communication technologies}

The integration of niche information and communication technologies into traditional energy systems enables data to be gathered and used to optimise the system in smarter (and potentially more local) ways, and provide greater flexibility and security. Alamaniotis [55] describes this integrated system as "the coupling of distribution grid with information and processing technologies for management of power generation, transmission and delivery", driven by data on energy quantities, costs and characteristics. The same ideas re-occur when elements and enablers of smart energy systems are discussed:

- "A smart system ... more driven by data and communication technologies" [17]

- "information fusion ... a reconstruction of the energy system with the information system" [16]

- "Energy internet ... information networks interact with power generation, transmission, and distribution systems aiming at optimizing power system operation." [54]

- "a smart city ... ICT applied to critical infrastructure components and services" [42]

Interviewees expressed similar thoughts, describing "an information data driven system" INT3, which is "... smart because it generates and consumes, within itself, data in real or near real time, to perform its complex function optimally- by some criteria.." INT1. They noted it includes "digital platforms for synthesising and assimilating data across a number of local energy vectors" INT4, or "an ICT layer ... that allows us to respond to the changing conditions in the local energy system - and that's the smartness" INT10. One interviewee 
also mentioned that the smartness came from "... collecting digital information from them and you have some ability to influence it [the energy system], based on that data." INT6

This last viewpoint reflects a common perspective in the literature, that a smarter energy system means capturing data in order to inform services and better operate the system [42]:

"Smart Energy is the application of real-time bi-directional communication of information to ensure the intelligent distribution of supply \& demand in the energy network" [16]

Two-way communication is noted as a feature that characterises smart energy, and smart grids in particular, [38,62], while various authors highlight the need for additional metering [41] and engagement to obtain feedback [63].

\subsubsection{Automation and self-regulation}

Interviewees also discussed smartness in terms of more active network management, implementing some degree of autonomy to keep local energy systems balanced and optimise resource use.

"...there's a degree of autonomy ... the system responds to its environment in that it tries to balance supply and demand, whereas a non-smart system simply doesn't" INT10

"...the [smart] system automatically controls itself to provide the services that are needed, so you're using technology to make the decisions." INT13

This fits closely with Ofgem's definition of smart as "something enabled by new technology" particularly where this "enables automatic control" [69], and descriptions of specific smart energy systems that include autonomous control elements, e.g. [37], used to optimise the operation of the system. This dynamic control also provides greater capacity to respond flexibly to (and therefore cope with) failure with individual elements of the system.

\subsubsection{Users}

While there was generally consensus around smartness relying on the generation and use of data derived from the integration of "smart" technologies into energy systems, a broader discussion emerged around the location of that smartness. Many interviewees articulated that wider aspects beyond the purely technical were an integral part of a smart energy system:

"you can also get the human aspect of it and what people want to do and why the empowerment of practices that they need to follow ...so it's kind of a combination of two things, the technical and the human aspect", INT9 


\subsubsection{Ability to learn user preferences}

In this new operating paradigm, energy systems are autonomously controlled in real time, informed by data collected from both network monitoring and users themselves, who provide information on their preferences that are developed into user profiles [37].

For one interviewee, a similar capability was manifest in peer-to-peer transactive energy marketplaces, where the smartness was due to the system being able to optimise against user preferences through minimal input, leveraging self-learning.

"...the minimum thing is providing that 'I want to buy solar power, I want to sell to my neighbours... so what are my preferences?' and set once and used continuously to learn ... in such a way that it optimises my own preferences." INT9

This perspective couples people with technology in defining the smartness, with users setting parameters, and technology learning and adapting based on revealed preferences.

\subsubsection{Supporting smarter decision making}

Alongside concepts of automation, some interviewees questioned the role of people in smart energy system operation, and their role in users of new energy system data to support more effective decision-making, planning, and governance processes.

“it's about information that's providing an awareness of consequences of decisions ... so the smartness comes from decision making by people that's informed by richer data and can take more factors into account." INT5

There was also agreement that the "smart" technology and any use of automation shouldn't make users feel stupid, but instead empower them through greater control and choice, helping them "access the benefits of a smart system in whatever way works for them" [17]. This would enable individuals to make more informed decisions and ensure that the energy services they receive are tailored to their priorities and needs.

\subsubsection{Institutional elements}

Across the literature and interviews it was clear that institutional infrastructure was considered a key part of the energy system:

"also includes the market structures, the regulation, the rules, the industry codes, it's all of those things that make that system work, along with the infrastructure, so it's all of that, in there because everything that happens within that system has got dependencies on all of those things and of course the consumers." INT1

"political, economic, social and technological dimensions are included in the energy chain. If the aim was only to deal with the technology of the energy chain, the word "energy infrastructure" would be a more accurate expression" [36] 
This section thus considers how institutional elements, including governance structures, ownership models, and stakeholders, might be arranged in new ways within smart local energy systems.

\subsubsection{Local governance}

Decision making at a local level is likely to affect how favourable conditions are for local energy systems. As Ofgem note:

"The prevalence of local [energy] in a country depends on that state's administrative, policy, governance and market arrangements." [19]

This can vary from one local authority to the next, though relationships between authorities can sometimes be forged due to shared energy needs (INT4). As the energy system transforms towards a more localised approach, such institutional and decision making infrastructure is likely to change with it.

"... to get a really SLES, they [decision makers] probably need to be interacting with other entities locally, whether it's the local council, whether it's community groups...." INT8

Recent recommendations from IGov describe a situation where:

"Distribution Service Providers (DSPs) would replace DNOs, to become coordinators of local energy systems, market facilitators and balancers. DSPs would implement the shift from the linear, top-down value chain of the energy system to one which places customers at its focus and values efficiency, flexibility and sustainability." [73]

\subsubsection{Commercial arrangements}

Alongside new local forms of governance, a degree of control of local energy systems can be maintained through local ownership of assets. One interviewee stated that:

“... you would expect there to be local ownership of demand assets ... of generation assets ... of storage" and, "[ownership and investment] at the systems level ... in a minority of cases." (INT10).

Such arrangements can help to foster engagement and enable profits to be kept within communities rather than channelled elsewhere by private companies as is often feared [40]. Alanne and Saari [36] also noted that although the common expectation is that "energy conversion technology should be owned by energy utilities, because they have expertise and other resources" to maintain and operate it, decentralising these functions would require the creation of new jobs and so boost the local economy. Presently though, local ownership is by no means a requirement of a local energy system; Devine-Wright and Wiersma [39] found that many decentralised energy projects they studied had sourced funds from elsewhere in 42 the country and beyond. 


\subsubsection{Local stakeholders}

Several interviewees discussed the role of communities and other local stakeholders in smart local energy systems. One participant described a recent policy shift from community towards local energy, highlighting key differences in terms the actors involved and the distribution of benefits:

"...local energy is... a slightly less radical version where local authorities are at the centre of managing and driving energy systems, maybe in partnership with private sector actors and civil society, but it places much more of a focal point role on existing institutions - public sector institutions, like councils - whereas community energy was much more about civic, grass roots organisations and citizens coming together and forming new kinds of organisations, with lots of assumptions around the sharing of benefits..." INT11

Other participants highlighted that local energy, unlike community energy, was geographically constrained, rather than focusing on communities of 'interest' or 'practice':

“...local implies a locality. Community implies a group that identify with it..." INT13

However, this does not preclude communities from engaging with local energy systems; localisation, with local authorities at the focal point, can make it easier for citizens and communities to interact, engage, and participate, delivering increased transparency and efficiency (in the energy system) and ultimately improving their neighbourhoods [74, 75].

Thus, a key element of local energy systems is the involvement of local stakeholders, including local citizens and communities, typically via the local authority [7].

\subsection{Regime boundaries}

When considering how boundaries are drawn around local energy systems, the concept of local may seem "self-evident" [39] but closer examination reveals inconsistencies and different perspectives. The ever-present, perhaps indisputable, factor is some form of spatial description or boundary.

\subsubsection{By geography}

One of the most common ways in which local was discussed was based around physical, map-based geography. Interviewees talked of putting a "circle around the evidence" to pinpoint the energy system (INT7), and the need for geographic boundaries (INT8, INT9), even if these might vary dependent on context. This was reflected in the literature by the use of similar terminology, e.g. "within a common geographical area" [19].

This focus on geographic demarcation of the SLES boundary makes this type of energy system transition distinct from others also emerging due to the rise in decentralised renewable generation. An example, highlighted in the interviews, compares SLES development to the renewable transition seen in Germany: 
"...the German renewable energy sector has taken off because of citizen funding and share offers and that's not been at a local basis at all, it's been people investing in wind energy or solar energy projects from all over the country..." INT5

However, there are a number of ways in which this geographically defined boundary around a SLES regime can be considered, as outlined in the following sections.

\subsubsection{By generation resources}

Proximity to energy generation can "enable a sense of connection" in customers, even where the supply is not directly or exclusively connected to the demand [76]. More commonly though, where supply is located close to demand to take advantage of the close physical connection. Local in these cases refers to "production where it is needed" [64] or 'decentralised energy' where energy is generated close to demand [36]. This can involve building a local energy system around a single nucleus e.g. "a large solar farm... a farm waste digester that gives you a source of gas or... an industrial process that gives you a source of waste heat" (INT5) or a network of multiple energy sources (e.g. solar panels on the homes of 'prosumers'). Such approaches help to minimise transmission and so make "economic and infrastructural sense" [40].

\subsubsection{By network infrastructure}

Local can also be considered in terms of the physical networks and infrastructure that enable energy to flow. As a key purpose of SLES is local balancing - "matching generation with demand at a local level to minimise the amount of electricity exported out of and imported into a local area" [76] - boundaries are often defined by network segment; e.g., all residents connected to the low voltage network beneath a particular electricity substation [63] or beneath a known supply bottleneck.

Considering local in this context also led interviewees to explicitly consider scale, for example, transmission level vs. distribution level vs. sub-station level:

"anything from the sort of lower, secondary sub-station which might be 200-300 homes, scaling up through a primary sub-station which is a few thousand homes and businesses and... probably back to the grid supply point... so that's a very electrical based definition of scale." INT10

Most interviewees were unable to discuss network infrastructure without considering the different scales at which these networks exist. This contrasts with the discussion around map-based geography, where people are probably internalising the concept of scale (as became apparent in the interviews - see Section 4.3.5), but not discussing this explicitly when considering local in terms of physical geography and place.

\subsubsection{By social constructs}

Local can also be defined through social constructs, determining boundaries more conceptually through social structures and networks, social identity, or by considering the people who can directly benefit from or participate in the SLES. Some interviewees discussed "local" in terms of the social context driven by place and identify, where the 
boundary can vary from a single street or estate up to a county or region, depending on the sense of engagement:

"...people say, for us local is our village and in other places, local is their region." INT9

"... it could be a city, a town, even a county, I suppose, but it's certainly got that influence of context and place" INT3

"...it's about the community feeling about the energy system in that area and so there is a community with a vested interest in their energy system." INT13

"people's boundaries don't stop just because there happens to be a grid supply point at the end of their road." INT8

Ofgem have recognised the importance of identity and engagement, defining local energy as:

"Energy arrangements led by (or for the benefit of) a local group and for the benefit of local consumers. A local group is a collection of people and organisations with shared interests in local energy outcomes within a common geographical area" [19]

Devine-Wright and Wiersma [39], however, noted a common view of local is "an indicator of place-based distinctiveness", raising the issue that if an energy system is truly able to address the "unique qualities and characteristics of different communities living in different spatial areas", it will by nature be bespoke and difficult to replicate.

\subsubsection{Scales of local}

Local energy system projects described in the literature vary wildly in scale, from single building systems to anything below the level of national energy infrastructure. There was general agreement among interviewees as well that the scale of "local" was somewhat ambiguous:

"... it doesn't have a clear meaning and it never will, so it could be 300 yards, it could be 30 miles, it could be three miles, it's some kind of suggestion of a geographical boundary of an identifiable area or place, but I don't think it will ever be exactly clear what its boundaries should be in any kind of uniform, replicable way." INT11

The interviewees were also asked specifically what they would consider as the upper and lower bounds in terms of the scale of local energy systems, which produced a wide range of responses:

\subsubsection{Local at the smallest scale}

"It would be something as tiny, for example, as a passive, mixed model energy generation \& supply housing complex, with $x$ number of families ... all connected into one, single energy system ... and let's hope we are not going to go as low in size as a single, small block, in an estate, in a big city." INT1 
"I would certainly argue that the individual house is part of this, if only because that's the ultimate, individual unit that we might think about replicating...." INT8

\subsubsection{Local at the biggest scale}

"To me, the biggest is a city region or geographical setting that has some boundaries drawn to it that are applicable to the energy sector, so it either is generation or it's regulation or it's consumption or tariffing governance or whatever." INT1

"I think local means that we're not getting about hundreds of people, in my conception. As soon as I say any of these things, I'm challenging myself thinking 'why can't local mean a whole municipality?' which I guess would be commonplace in Germany and Scandinavia and elsewhere." INT5

"If it was Surrey-wide or Oxford-wide, is that local or is that too big? ... Where you end that scale, as you get bigger, to the county scale and others is more tricky..." INT8

Taking the smallest and largest examples given, this covers the same range of scales as is present in the literature:

"what's behind the meter is local, but in some sense, anything that's below the transmission active management is local, so those are kind of pushing towards each other." INT6

\section{Discussion}

In this paper we have examined how socio-technical regimes associated with smart local energy systems are conceptualised, and explored how they interact with wider pressures to deliver value not realised (or not maximised) by incumbent arrangements. In this section we discussion four key contributions of the paper: defining the key characteristics of smart local energy regimes; exploring relationships between landscape and local pressures; linking regime processes to desired outcomes; and the development of a conceptual framework for exploring emergent SLES.

\subsection{Characterising SLES regimes}

While there is not one clear definition of what a smart local energy system is, the findings provide insight into the key elements that make energy systems "smart" and "local". Elements that deliver system "smartness" include the use of new information and communication technologies as well as automation and self-regulation operating paradigms to help improve system operation. In some instances, this will rely on autonomous operation, in others through the use of new data and insights to inform more effective decision making. Within a SLES this "smartness" enables increasingly localised forms of system balancing and network management, supported by flexibility across energy vectors. "Localness" is characterised by more local forms of system management, operation, governance, 
ownership, and engagement. It is also defined by the geographical boundary around the system, through consideration of generation assets, network infrastructure, or social identity.

Drawing on the wider theoretical framing provided by the MLP (outlined in Section 2), Figure 3 shows how the SLES regimes incorporate multiple niche technologies, business models, and governance structures to enable new forms of localised energy system operation and optimisation (e.g. local and automated forms of network management across energy vectors), smarter decision making and planning, by new actors (e.g. local authorities, other local stakeholders), and engaging users in new ways. This emerging SLES regime exists

Through integrating these niche innovations in new and context specific ways, SLES regimes are anticipated to deliver benefits (outlined in Section 4.1) that meet landscape pressures related to reducing carbon emissions (i.e. addressing climate change and net-zero legislations), delivering environmental eco-system benefits (e.g. aligned with the Sustainable Development Goals), supporting a Just transition, providing energy services more efficiently and driving economic prosperity, and increasing resilience and security of supply.

However, this conceptualisation of SLES regimes as the result of purposive transitions to deliver multiple benefits (or meet multiple landscape pressures) raises a number of questions related to: (1) whether some outcomes are more highly prioritised than others, (2) how trade-offs are managed and by whom, and (3) how local needs can be aligned with national or global pressures. As outlined in Section 4.1.5, SLES are anticipated to deliver against local priorities as well as wider landscape pressures, so the interaction of these drivers at different scales needs to be considered. The following sections explore these issues in greater detail.

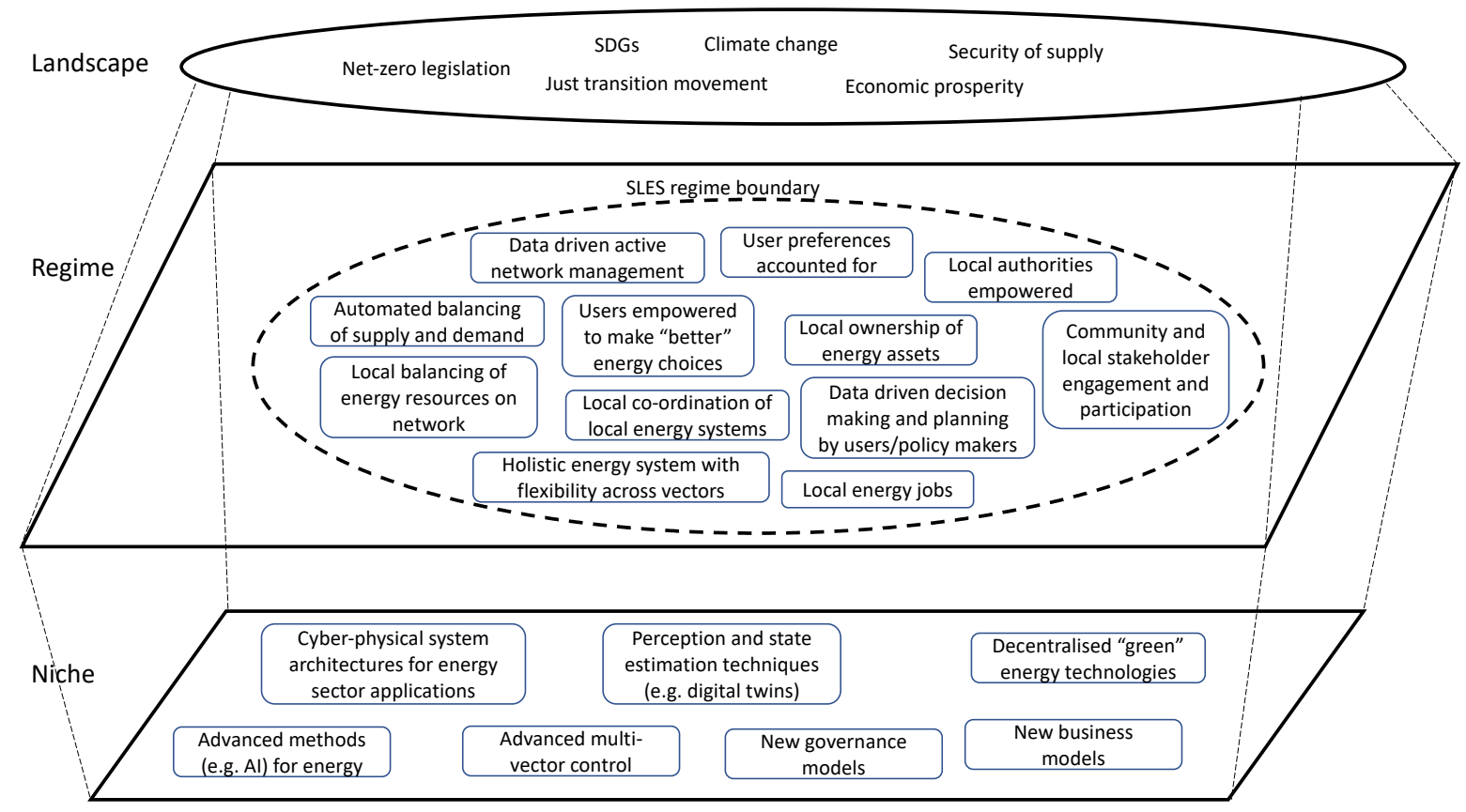

Figure 3: An MLP perspective of SLES 


\subsection{Landscape and local pressures}

2 Energy system transitions are typically considered purposive, driven by concern for climate change, energy prices, security of supply issues, etc., deliberately intended and pursued to address these landscape level societal expectations, interests, or pressures [77, 78]. However, in the case of smart local energy systems, pressures from within the regime (rather than the exogenous landscape) are also shaping SLES innovation to help meet local priorities and needs. This type of transition, described by [77] as "endogenous renewal", means that innovation and transition could be steered by interests, values, and practices prevailing in the incumbent regime, which may counter wider landscape pressures necessitating more radical transition.

While the primary outcome of traditional energy systems (i.e. not necessarily 'smart' or 'local') is to enable energy services to be delivered to end-users of the system [79, 80]; the transition toward SLES means these systems' telos (or principal reason for being) become less clear cut. Although energy service delivery will always be a necessary outcome for any energy system, the provision of services beyond energy will likely become increasingly important, or even dominant. As noted in Section 4.1.1, one interviewee explored the possibility of data as a service becoming more valuable than energy as a service. While this remains a hypothetical situation today, it raises interesting questions around how value is determined, and by/for whom. For example, it is possible that the value of data may be greater to actors or organisations involved in developing and managing the energy system and associated services, while the value of energy remains the main priority for end energy users. Therefore, as more actors become engaged in the energy sector through the transition toward SLES, it is possible that identifying the ultimate purpose of the system becomes increasingly challenging.

The findings from this work also suggest a blurring between primary outcomes and key cobenefits that smart local energy systems are expected to deliver. In addition to delivering energy services in more effective or efficient ways, benefits include reducing costs and making energy more affordable, addressing fuel poverty and energy equity issues, driving carbon emissions reductions and enhancing wider environmental eco-system services, increasing local resilience and the ability to cope with failure, and helping local communities meet these fundamental needs in context specific ways. These objectives set the broader context in which the underlying outcome (of providing energy and related services to system users) are expected to be delivered. Thus, a SLES meets its basic objective, whilst also delivering other outcomes, enabled by its "smartness" and "localness".

A 'smart' energy system is expected to enable better and more effective use of resources through being smart. This increase in effectiveness can take many forms. It can mean reducing costs or mitigating losses. It can mean producing larger benefits for individuals, for the system owners and operators, or for the wider world. It can mean producing the right benefits for these groups, more consistent benefits, or a wider range of benefits. Ultimately, this view of smart is about efficiency: doing more with less. Applying 'smart' principles properly means making the best use of resources through improved information and enhanced decision making and control capabilities, to maximise whole system benefits for all system stakeholders. As such, smart may only be attainable temporarily; an energy system 
may cease to be smart if it fails to continually evolve to take advantage of new technologies and opportunities to improve.

Similarly, the driver for 'local' seems to be to deliver additional benefits, particularly around the ability of the system to deliver value to local actors, and to do so more inclusively across communities involved. This raises interesting questions around how such inclusive value can be realised, at what scale of locality, and engaging which actors. It also raises concerns related to vested interests, and the interaction between SLES outcomes and wider system outcomes. For example, while the literature considers potential social and equity benefits for actors within a local energy system regime (e.g. making energy more affordable, addressing fuel poverty issues, delivering benefits back into the community), there was some concern expressed in the interviews around the potential for inequalities to emerge between localities, and for some areas to benefit at the expense of others. Given that many smart local energy system demonstration projects occur in areas with existing capacity and resource to deliver them, this raises questions around need for policy or other mechanisms to prevent other, less well-resourced areas from being left behind.

Another example of the need to consider scale, actors, vested interests, and inequalities relates to management and governance issues. While energy systems have traditionally been operationally managed using top down practices, the shift toward smart local energy systems is encouraging a bottom up management practice (e.g. to balance supply and demand locally, optimise local resource use, minimise network constraints). Given that national and local networks may experience constraints and require ancillary services at different times and for different durations, this opens up a range of questions about how smart local energy system assets might engage in different markets (at different scales) or provide services at different scales, and how prioritisation between participation in these different markets can be negotiated. Furthermore, the increasing involvement of local authorities in SLES decision making processes (e.g. local area and energy planning) open up questions around how policies, regulation, and planning are undertaken, at what scale, and by which actors.

There is currently no clear framework for considering the multiplicity of SLES benefits / outcomes, their origin (e.g. landscape pressures, regime challenges), their beneficiaries (e.g. incumbent actors, local communities, etc.), and their interactions or trade-offs with eachother (e.g. should carbon reductions, cost minimisation, or equity be prioritised) and across scales (e.g. if maximising the use of renewable energy locally results in sub-optimal national operation). Further research is needed to develop this framework, which would help policymakers align local and national outcomes and negotiate trade-offs between outcomes.

\subsection{Linking purpose (and outcomes) to process}

Despite the expectation that SLES will deliver a wide range of benefits, the findings presented very little insight into the process by which the arrangements of elements within the SLES regime (e.g. hardware, software, processes, procedures, people that are required for the operation of that system) would enable this. For example, Figure 4 presents a depiction of how different dynamics of ownership between the same elements might affect the outcomes achieved through a local energy system. 

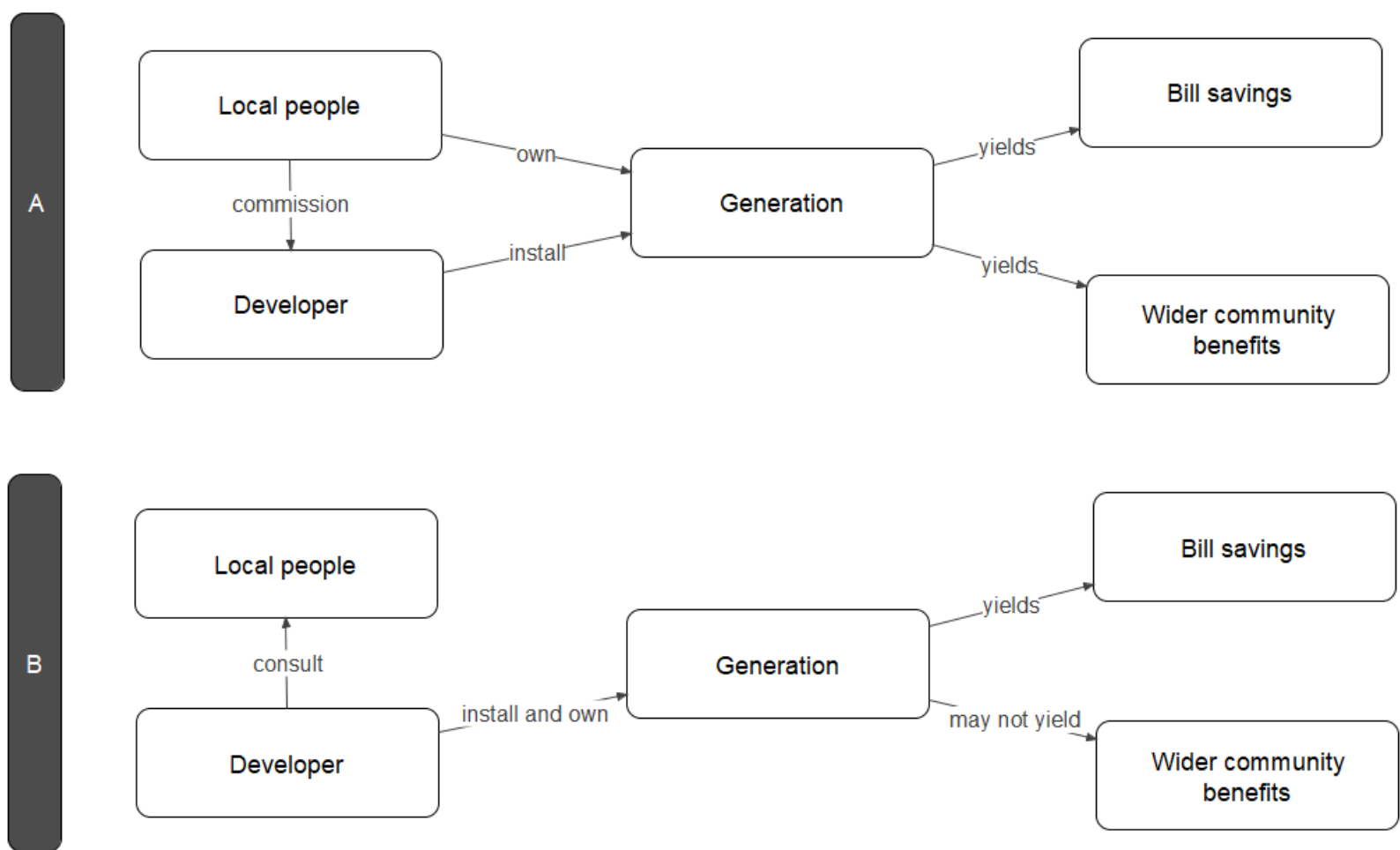

Figure 4: The elements are interconnected (represented by arrows) differently in arrangement $A$ and $B$, leading to potentially different outcomes becoming viable (please note this is for illustrative purposes only)

Similarly, Figure 5 shows how certain 'smart' elements are linked to each other, and to outcomes, by considering pervasive information and communication technologies and data generation embedded within SLES regimes. The way in which these may interconnect and interact with existing elements is not clear or linear, and may introduce entirely new value chains, goals/purposes, and business models into the SLES.

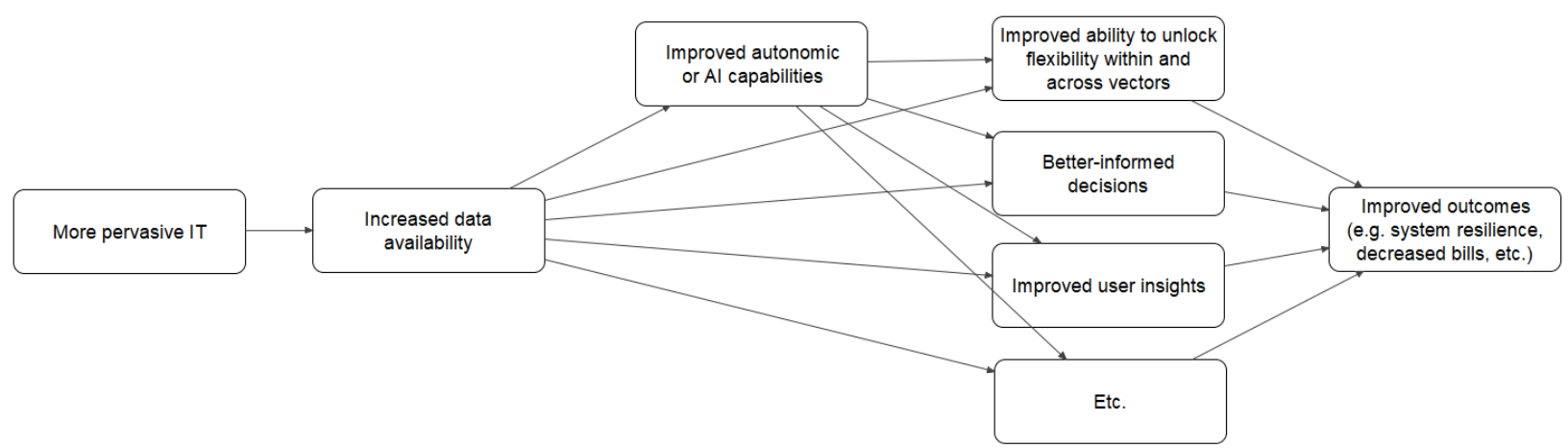

Figure 5: Causal model illustrating how more pervasive IT in a smart energy system might be expected to lead to certain outcomes

There also appears to be an embedded assumption that the availability and use of data will lead to a range of positive outcomes (e.g. maximising the use of local resources, delivering environmental ecosystem benefits). However, there is very little discussion of what data is 
required and how it should be used to ensure these benefits are realised; for example, to deliver environmental system benefits it is likely that data beyond energy system data will be required. Furthermore, there is a risk that considering these elements of 'smartness' only within the 'local' energy system context could lead to better outcomes at the local level but worse overall outcomes. To ensure SLES can deliver both local and national benefits, it is important to understand what the data requirements are, where they might come from, who owns the data, and what rights or permissions over use may exist. The governance arrangements for managing complex data sharing requirements are unclear at present.

\section{$9 \quad 5.4$ Conceptual Framework for SLES}

Drawing together the insights from Sections 5.1, 5.2 and 5.3, we have created a conceptual framework for examining SLES transitions (see Figure 6). This brings together the theoretical grounding provided by the MLP (outlined in Section 5.1), but also incorporates elements specific to SLES transitions, including (1) the regime level pressures (potentially from incumbent actors) which count interact with the wider landscape pressures to either promote or constrain radical transition as discussed in Section 5.2; (2) the local impacts SLES are anticipated to deliver as well as the impacts on the wider energy system, resulting from the specific arrangement of smart, local and energy system regime elements, as discussed in 5.3 and (3) the interactions that SLES have with the wider energy (and related) systems that they exist and operated within.

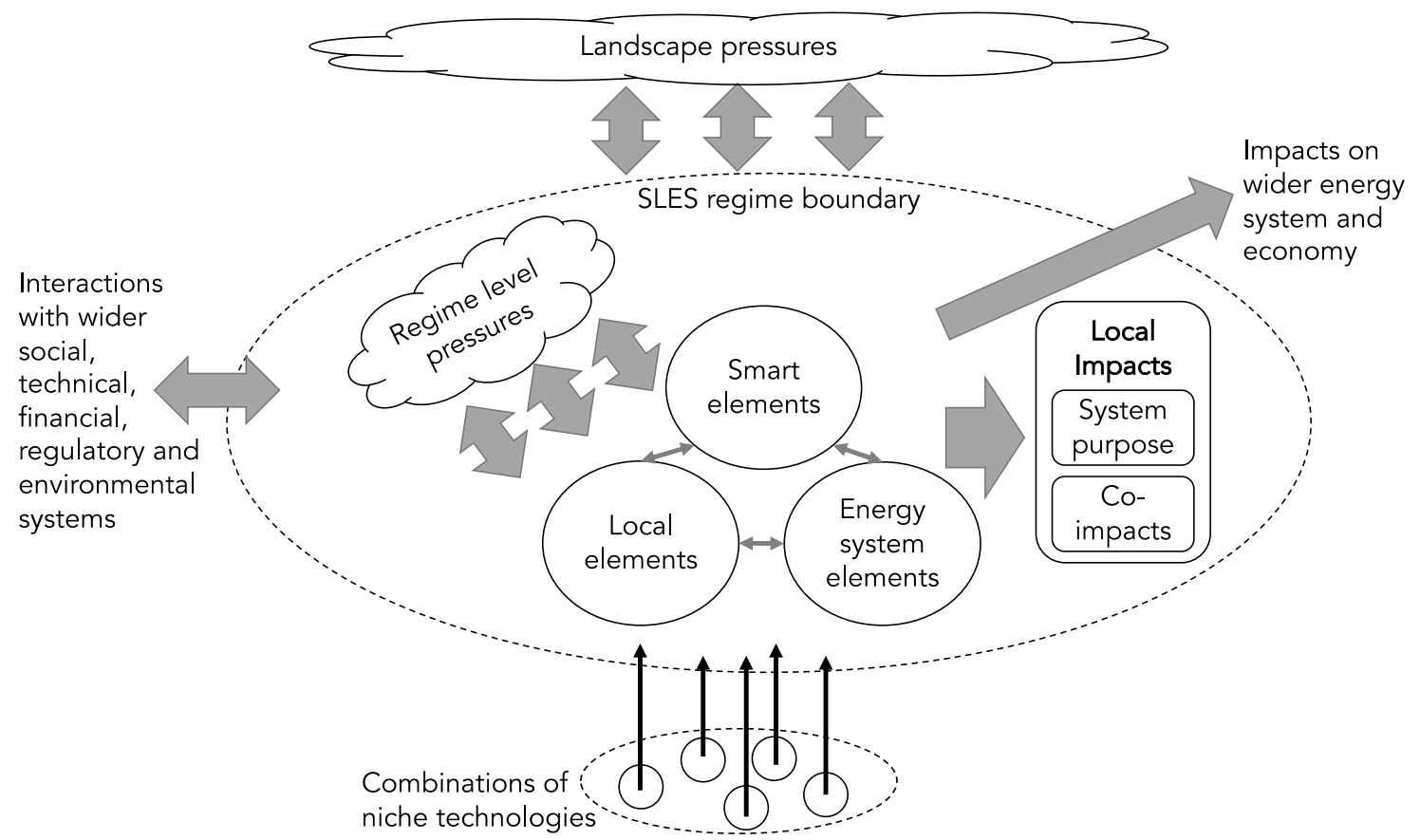

Figure 6: Conceptual framework for exploring interactions across and within the multiple levels of SLES

\section{Conclusions}

While SLES are expected to deliver a wide range of benefits, a number of issues need 
and environmentally sound transition to net-zero. The following paragraphs outline the managerial and policy implications for delivering SLES, the limitations of the current study, and opportunities for further research.

\section{$4 \quad 6.1$ Managerial and policy implications}

5 Considering the potential for SLES to support transformative change, it's important for policy

6 to consider how innovative SLES approaches may be legitimised and scaled in terms of

7 direction, pace, and speed to deliver net-zero. This requires extending traditional innovation

8 policy approaches to consider four additional dimensions highlighted in the current study: (1)

9 directionality, (2) demand articulation, (3) policy co-ordination, and (4) reflexivity [81].

\subsubsection{Directionality}

This considers the creation of a shared vision around the goal of SLES. As highlighted in this work, SLES are capable of delivering against a wide range of different outcomes, which may not all be compatible, requiring prioritisations between different goals, and re-organisation of SLES elements to deliver them. To mitigate against failure, policy frameworks must articulate and shape this vision, accounting for the diversity of perspectives, creating a structure within which different actors can work together to drive transformative change. Given the "localness" of SLES, this means accounting for citizen and community objectives, as well as sectoral, regional, and national priorities.

SLES "smartness" can help optimise the system according to these objectives. However, given than SLES are not operating in isolation, but are connected to the wider energy system, this requires a consideration of scale; it is likely that conditions or parameters relating to the wider system will be necessary to inform SLES optimisation (and indeed that SLES optimisation may impact the wider energy system). Protocols for sharing data within the SLES and between the SLES and wider system must enable the necessary data to be available and usable in real time. Care must be taken in the design phase to ensure the SLES has access to the data streams required for its optimisation, which may require additional monitoring equipment to be installed.

This raises further policy implications associated with the real time sharing of operational data between actors within the SLES and between the SLES and wider network; data ownership must be established, value streams associated with the data needs to be considered (e.g. does it have commercial value or is it presumed open), care taken to ensure customer protection is maintained, and standards may need to be developed to ensure available data is usable within the cyber physical framework being implemented.

\subsubsection{Demand articulation}

This considers "users" of SLES, and the demand for such systems which may be necessary to ensure continued uptake and innovation. Referring back to Figure 4, it's important that SLES are designed, managed, and governed in a way that local stakeholders perceive benefits. These local stakeholders, who can be considered "users" of SLES, include citizens, community groups, local authorities, and local businesses, who may all benefit directly (e.g. 
cities with cleaner air) from SLES. To support innovation and roll out of SLES, policy frameworks, regulations, market access and governance structures must ensure that SLES are able to attend to these demand signals.

4

5

6

7

8

9

10

\subsubsection{Policy-co-ordination}

This calls for policy co-ordination across different systemic levels, which for SLES requires thinking about the potential for additional institutional implications resulting from a shift toward more localised systems. This may call for more locally relevant policy and regulation, more localised planning (for example to deliver to locally specific goals and purposes), and a greater involvement of local authorities at different scales in governing the operation of (and investment in) local energy systems. The exact nature of this involvement within a local energy system is unclear, and needs to be more explicitly considered alongside the broader goals of both the local and national energy systems, examining how local decision making and policy setting could support the delivery of these goals.

The "local" element of SLES raises further implications related to equity and governance. From a technical perspective, the elements of a local energy system may be understood by considering how physical resources (such as supply, demand, and storage technologies in the context of electricity or heat) are connected to local energy infrastructure. As the interviews highlighted, the precise arrangement of physical networks may be an important determinant of the ultimate structure of local energy system. The position on a substation, for example, may decide whether two homes or business are more or less likely to be interconnected through a local energy market, and may therefore determine whether they are able to offer (and benefit from providing) energy or flexibility services. While SLES may support more localised and active network management, policy makers must consider how this impacts on competitive access to markets (operational today and in the future) within and between local energy systems, and whether some actors may benefit and other lose out due to the technical infrastructure arrangements.

\subsubsection{Reflexivity}

This calls for governance structures and regulations that enable experimentation, learning and adaptation. For SLES this is particularly pertinent for two key reasons. The first is that SLES are still incredibly new, and while they are anticipated to deliver a wide range of outcome benefits to a wide range of actors, it's not yet clear whether their current arrangements can or will deliver expected outcomes, and whether there may be unanticipated and unintended negative consequences. To ensure SLES continue to deliver against their shared goals and objectives, policy structures need to be adaptive to lessons learnt during this early stage of SLES development. This also means ensuring that the necessary data is collected to allow SLES to be effectively evaluated.

Further design considerations for SLES emerge when considering the use of 'smart' technologies (e.g. to collect, store, and share data) and processes (e.g. artificial intelligence and autonomous decision making capabilities) to optimise the system along a number of key outcome variables. This is because the available energy resources, data, and intended outcomes may change over time, so the design of SLES cyber physical infrastructure must 
1 be agile, responsive, and flexible to these changing conditions, allowing the system to

2 remain "smart" as things change.

\section{$3 \quad 6.2$ Limitations and further work}

4 This work has opened a structured discourse around smart local energy systems, their

5 purpose/goals, and the elements and interconnections they embody. However, we recognise

6 that this initial exploratory study presents a number of limitations, and consequently,

7 opportunities for further research to extend the insights generated here.

8

9 While the work did aim to capture diverse perspectives of SLES through both interviews and literature review, on reflection it is overly informed by academic insights. The literature review did include grey literature as well as academic, however, the inclusion of insights from policy makers, practitioners, and others working at the forefront of SLES development (e.g. via interviews or case study work research) would add value. Similarly, it would be useful to explore how insights from different cultural and geographical contexts globally differ, and how SLES (or elements of SLES) are evolving differently in different contexts.

This work has also raised questions around the origin of pressures (and anticipated benefits) driving SLES transition. Further work exploring where these pressures originate (e.g. from incumbents within the existing regime, the landscape, or elsewhere) and who benefits (and who will pay) from the SLES regimes created in response to these pressures would be useful to understand: (1) conceptually what SLES regimes look like and how they are different to current regimes (e.g. are they purposive, are they capable of delivering radical change, or are they just incumbents responding to threats in the regime to maintain stability and power) and (2) systematically the benefits (and negative consequences) that are expected to accrue - what and to who - to explore the distributional effects and issues related to energy justice.

Furthermore, this work didn't seek to understand how smart local energy systems came to be (e.g. through alignment of combinations of social and technical niches) and didn't consider in detail how the presence or absence of different SLES elements enable outcomes to be delivered. Figure 4 and Figure 5 illustrate how these pathways could be very important in allowing outcomes to be realised; to ensure the wider ranging and more nuanced goals of smart local energy systems can be successfully delivered on, it is important that system elements and their interconnections are understood, and mapped to these intended outcomes. Further work is recommended to explore in more detail the pathways by which the presence (or absence) of 'smart' and 'local' elements (including how they are connected) can deliver beneficial outcomes and mitigate negative ones. 


\section{References}

1. Edenhofer, O., Climate change 2014: mitigation of climate change. Vol. 3. 2015: Cambridge University Press.

2. Rogelj, J., et al., Energy system transformations for limiting end-of-century warming to below 1.5 C. Nature Climate Change, 2015. 5(6): p. 519.

3. Patterson, J.J., et al., Political feasibility of 1.5 degrees $C$ societal transformations: the role of social justice. Current Opinion in Environmental Sustainability, 2018. 31: p. $1-9$.

4. van Veelen, B. and D. van der Horst, What is energy democracy? Connecting social science energy research and political theory. Energy Research \& Social Science, 2018. 46: p. 19-28.

5. Howell, S., et al., Towards the next generation of smart grids: Semantic and holonic multi-agent management of distributed energy resources. Renewable and Sustainable Energy Reviews, 2017. 77: p. 193-214.

6. Parag, Y. and B.K. Sovacool, Electricity market design for the prosumer era. Nature Energy, 2016. 1(4): p. 1-6.

7. Devine-Wright, P., Community versus local energy in a context of climate emergency. Nature Energy, 2019. 4(11): p. 894-896.

8. BloombergNEF. Digitalization of Energy Systems. 2017 [cited 2019 May]; Available from: https://about.bnef.com/blog/digitalization-energy-systems/.

9. Energy Consumer Market Alignment Project (EC-MAP). New policy for an era of energy digitalization: Power. 2018 [cited 2019 May]; Available from: http://ecmap.org/wp-content/uploads/2018/10/Power-Whitepaper.pdf.

10. IEA. Digitalization and Energy - Technology report. 2017 [cited 2020 December]; Available from: https://www.iea.org/reports/digitalisation-and-energy

11. Pullum, L.L., Big Data Analytics in the Smart Grid. 2018.

12. Flett, G., N. Kelly, and R. McGhee, Review of UK Energy System Demonstrators. 2018, UKERC.

13. Frame, D., et al., Innovation in regulated electricity distribution networks: A review of the effectiveness of Great Britain's Low Carbon Networks Fund. Energy Policy, 2018. 118: p. 121-132.

14. Lund, H., et al., Smart energy and smart energy systems. Energy, 2017. 137(September): p. 556-565.

15. Bačeković, I. and P.A. Østergaard, Local smart energy systems and cross-system integration. Energy, 2018. 151(2018): p. 812-825.

16. Haitao, L., et al., Research on the conceptual model of smart energy system. 2017 IEEE Conference on Energy Internet and Energy System Integration, EI2 2017 Proceedings, 2018. 2018-January: p. 1-6.

17. Office of Gas and Electricity Markets (Ofgem). Upgrading Our Energy System: Smart Systems and Flexibility Plan. 2017 [cited 2019 May]; Available from: https://assets.publishing.service.gov.uk/government/uploads/system/uploads/attachm ent data/file/633442/upgrading-our-energy-system-july-2017.pdf

18. Connolly, D., H. Lund, and B.V. Mathiesen, Smart Energy Europe: The technical and economic impact of one potential $100 \%$ renewable energy scenario for the European Union. Renewable and Sustainable Energy Reviews, 2016. 60: p. 1634-1653.

19. Office of Gas and Electricity Markets (Ofgem). Ofgem's Future Insights Series: Local Energy in a Transforming Energy System. Ofgem 2017 [cited 2019 May]; Available from: https://www.ofgem.gov.uk/system/files/docs/2017/01/ofgem future insights series 3 local energy final 300117.pdf. 
20. Geels, F.W., Technological transitions as evolutionary reconfiguration processes: a multi-level perspective and a case-study. Research Policy, 2002. 31(8): p. 12571274.

21. Geels, F.W., From sectoral systems of innovation to socio-technical systems: Insights about dynamics and change from sociology and institutional theory. Research Policy, 2004. 33(6): p. 897-920.

22. Geels, F.W., Disruption and low-carbon system transformation: Progress and new challenges in socio-technical transitions research and the Multi-Level Perspective. Energy Research \& Social Science, 2018. 37: p. 224-231.

23. Sovacool, B.K., et al., Beyond cost and carbon: The multidimensional co-benefits of low carbon transitions in Europe. Ecological Economics, 2020. 169: p. 106529.

24. Geels, F.W. and J. Schot, Typology of sociotechnical transition pathways. Research Policy, 2007. 36(3): p. 399-417.

25. Geels, F.W., Ontologies, socio-technical transitions (to sustainability), and the multilevel perspective. Research Policy, 2010. 39(4): p. 495-510.

26. Geels, F.W., et al., Sociotechnical transitions for deep decarbonization. Science, 2017. 357(6357): p. 1242-1244.

27. Markard, J., R. Raven, and B. Truffer, Sustainability transitions: An emerging field of research and its prospects. Research Policy, 2012. 41(6): p. 955-967.

28. Köhler, J., et al., An agenda for sustainability transitions research: State of the art and future directions. Environmental Innovation and Societal Transitions, 2019. 31: p. 1-32.

29. Rip, A., R.P.M. Kemp, and R. Kemp, Technological change. Human choice and climate change. Vol. II, Resources and Technology, 1998: p. 327-399.

30. Greenhalgh, T., et al., Storylines of research in diffusion of innovation: a metanarrative approach to systematic review. Social science \& medicine, 2005. 61(2): p. 417-430.

31. Greenhalgh, T., et al., Diffusion of innovations in health service organisations: a systematic literature review. 2008: John Wiley \& Sons.

32. Wong, G., et al., RAMESES publication standards: meta-narrative reviews. BMC medicine, 2013. 11(1): p. 20.

33. Thomas, J., J. Brunton, and S. Graziosi, EPPI-Reviewer 4.0: software for research synthesis. EPPI-Centre Software. London: Social Science Research Unit. Institute of Education, University of London, 2010.

34. Walsham, G., Interpreting Information Systems in Organizations. . 1993, Chichester: Wiley.

35. Fisher, M., et al., Using qualitative research in systematic reviews: Older people's views of hospital discharge. London: Social Care Institute for Excellence, 2006.

36. Alanne, K. and A. Saari, Distributed energy generation and sustainable development. Renewable and Sustainable Energy Reviews, 2006. 10(6): p. 539-558.

37. Ding, Y., et al., A Smart Energy System : Distributed Resource. Management.

38. Hvelplund, F., et al., Policies for a transition to $100 \%$ renewable energy systems in Denmark before 2050. 2011. 108-108.

39. Devine-Wright, P. and B. Wiersma, Opening up the "local" to analysis: Exploring the spatiality of UK urban decentralised energy initiatives. Local Environment, 2013. 18(10): p. 1099-1116.

40. Julian, C., Creating Local Energy Economies: Lessons from Germany. p. 26.

41. Murphy, G., S.P.E. Networks, and P. Way, Ashton Hayes Smart Village Enquiry please contact.

42. Albino, V., U. Berardi, and R.M. Dangelico, Smart Cities: Definitions, Dimensions, Performance, and Initiatives. Journal of Urban Technology, 2015. 22(1): p. 3-21.

43. Hargreaves, N., J. Chilvers, and T. Hargreaves, "What's the meaning of 'smart'? A study of smart grids":Sociotechnical Report. 2015: School of Environmental Sciences, University of East Anglia. 114. 
44. Frame, D., K. Bell, and S. McArthur, A Review and Synthesis of the Outcomes from Low Carbon Networks Fund Projects. Ukerc, 2016.

45. Dong, D., et al., Simulation study of integrated smart energy systems. 2017 IEEE Innovative Smart Grid Technologies - Asia: Smart Grid for Smart Community, ISGTAsia 2017, 2018: p. 1-6.

46. Flett, G. and E. Systems, Review of UK Energy System Demonstrators. 2018(November).

47. Jones, S., et al., A system design for distributed energy generation in low temperature district heating (LTDH) networks. 2017.

48. Neves, A.R. and V. Leal, An exploratory study on energy sustainability indicators for local energy planning. WIT Transactions on Ecology and the Environment, 2009. 120: p. 611-622.

49. Neves, A.R., V. Leal, and J.C. Lourenço, A methodology for sustainable and inclusive local energy planning. Sustainable cities and society, 2015. 17: p. 110-121.

50. Ren, $\mathrm{H}$., et al., A mixed-integer linear optimization model for local energy system planning based on simplex and branch-and-bound algorithms, in Life System Modeling and Intelligent Computing. 2010, Springer. p. 361-371.

51. Connolly, D., et al., Smart energy systems: holistic and integrated energy systems for the era of $100 \%$ renewable energy. 2013.

52. Gruber, J.K., et al., Advanced building energy management based on a two-stage receding horizon optimization. Applied energy, 2015. 160: p. 194-205.

53. Spielmann, V., et al. A highly transparent method of assessing the contribution of incentives to meet various technical challenges in distributed energy systems. VDE.

54. Alamaniotis, M., D. Bargiotas, and L.H. Tsoukalas, Towards smart energy systems: application of kernel machine regression for medium term electricity load forecasting. SpringerPlus, 2016. 5(1): p. 58.

55. Alamaniotis, M. and L.H. Tsoukalas. Implementing smart energy systems: Integrating load and price forecasting for single parameter based demand response. IEEE.

56. Counsell, J.M., A.K. Ameer, and M.J. Stewart, Advanced Control of a fully integrated Renewable and CHP Heated, Cooled and Powered building. 2016.

57. Koirala, B.P., et al. Assessment of integrated community energy systems. IEEE.

58. Dincer, I. and C. Acar, Smart energy solutions with hydrogen options. International Journal of Hydrogen Energy, 2018. 43(18): p. 8579-8599.

59. Menniti, D., et al. A Real-Life Application of an Efficient Energy Management Method for a Local Energy System in Presence of Energy Storage Systems. IEEE.

60. Woltmann, S., et al., Agent Based Simulation Model of Virtual Power Plants for Greener Manufacturing. Procedia CIRP, 2018. 69(1): p. 377-382.

61. Zhou, Y., et al., A robust optimization approach for integrated community energy system in energy and ancillary service markets. Energy, 2018. 148: p. 1-15.

62. Ahuja, K. and A. Khosla, Network selection criterion for ubiquitous communication provisioning in smart cities for smart energy system. Journal of Network and Computer Applications, 2019. 127: p. 82-91.

63. Boait, P., et al., The Practice and Potential of Renewable Energy Localisation: Results from a UK Field Trial. Sustainability, 2019. 11(1): p. 215.

64. E.ON. Local Energy Systems / What are local energy systems? - E.ON. [cited 2019 May]; Available from: https://www.eon.se/en US/samhaelle---utveckling/local-energysystems/the-future-is-local.html.

65. Arnold, J.C., Larry, Achieving a smart energy ecosystem. Power Engineering International, 2010. 18(5): p. 32-38.

66. Department of Energy \& Climate Change. Annual Energy Statement DECC Departmental Memorandum. 2010 [cited 2019 May]; 1-28]. Available from: https://www.gov.uk/government/publications/annual-energy-statement-2010.

67. Knight, R. Smart Systems in the UK context - an ETI view. 2012 [cited 2019 May]; Available from: https://s3-eu-west- 
1.amazonaws.com/assets.eti.co.uk/legacyUploads/2014/03/Smart Cities Richard K night 17th April 2012.pdf.

68. Scottish Power Energy Networks. Accelerating Renewable Connections (ARC) ARC - Closedown Report. 2017 [cited 2019 May]; Available from: https://www.spenergynetworks.co.uk/userfiles/file/ARC Closedown Report.pdf.

69. Office of Gas and Electricity Markets (Ofgem). Upgrading Our Energy System: Smart Systems and Flexibility Plan. Call for Evidence Question Summaries and Response from the Government and Ofgem. Ofgem 2017 [cited 2019 May]; Available from: https://www.ofgem.gov.uk/system/files/docs/2017/07/ssf plan - summariesresponses.pdf.

70. Hvelplund, F., et al., Policies for a transition to $100 \%$ renewable energy systems in Denmark before 2050. 2011, CEESA. Department of Development.

71. Menniti, D., et al. A Real-Life Application of an Efficient Energy Management Method for a Local Energy System in Presence of Energy Storage Systems. 2018.

72. Ding, Y., et al., A Smart Energy System: Distributed Resource Management, Control and Optimization, in 2011 2nd leee Pes International Conference and Exhibition on Innovative Smart Grid Technologies. 2011.

73. Willis, R., et al., Enabling the transformation of the energy system : Recommendations from IGov. IGov, 2019(April).

74. Busche, S., Clean Energy Policy Analyses: Analysis of the Status and Impact of Clean Energy Policies at the Local Level. 2010, National Renewable Energy Lab. (NREL), Golden, CO (United States).

75. Julian, C., Creating Local Energy Economies: Lessons from Germany. 2014: p. 26.

76. Regen. Local supply: Options for selling your energy locally. [cited 2019 May]; 28]. Available from: https://www.regen.co.uk/wpcontent/uploads/REGEN Local Supply FINAL.pdf.

77. Smith, A., A. Stirling, and F. Berkhout, The governance of sustainable socio-technical transitions. Research Policy, 2005. 34(10): p. 1491-1510.

78. Kern, F. and J. Markard, Analysing Energy Transitions: Combining Insights from Transition Studies and International Political Economy, in The Palgrave Handbook of the International Political Economy of Energy, T. Van de Graaf, et al., Editors. 2016, Palgrave Macmillan UK: London. p. 291-318.

79. Groscurth, H.M., T. Bruckner, and R. Kümmel, Modeling of energy-services supply systems. Energy, 1995. 20(9): p. 941-958.

80. Fell, M.J., Energy services: A conceptual review. Energy research \& social science, 2017. 27: p. 129-140.

81. Weber, K.M. and H. Rohracher, Legitimizing research, technology and innovation policies for transformative change: Combining insights from innovation systems and multi-level perspective in a comprehensive 'failures' framework. Research Policy, 2012. 41(6): p. 1037-1047. 


\section{Appendix}

\section{Search strategy}

3 In the first instance, the search for the seminal studies in this area were identified by the use

4 of the exact terms of "smart energy", "local energy", "smart energy system", "local energy

5 system" and "smart local energy system" in the following databases:

\section{Databases}

- Scopus

- Web of science

- Ei Compendex

- Engineering Village GEOBASE

- IBSS

- Sociological Abstracts

- $\mathrm{ABI} /$ Inform

- Periodical Abstracts PlusText

- Applied Science \& Technology Abstracts

- Journal of Economic Literature

- Current Abstracts 


\section{Websites}

- UK Energy Research Centre http://www.ukerc.ac.uk/

- IEEE Power \& Energy Society https://www.ieee-pes.org/

- Department for Business, Energy \& Industrial Strategy

https://www.gov.uk/government/organisations/department-for-business-energy-and-

industrial-strategy

- Ofgem https://www.ofgem.gov.uk/

- Citizens Advice https://www.citizensadvice.org.uk/

- Sustainability First http://www.sustainabilityfirst.org.uk/

- Distribution Network Operators

- National Grid https://www.nationalgrid.com/

- Cambridge Energy Policy Research Group working papers

https://www.eprg.group.cam.ac.uk/

- European Commission Research and Innovation (Energy) https://ec.europa.eu/research/energy/index.cfm

- US Department of Energy (including SciTech Connect) https://www.energy.gov/ 


\section{Search results}

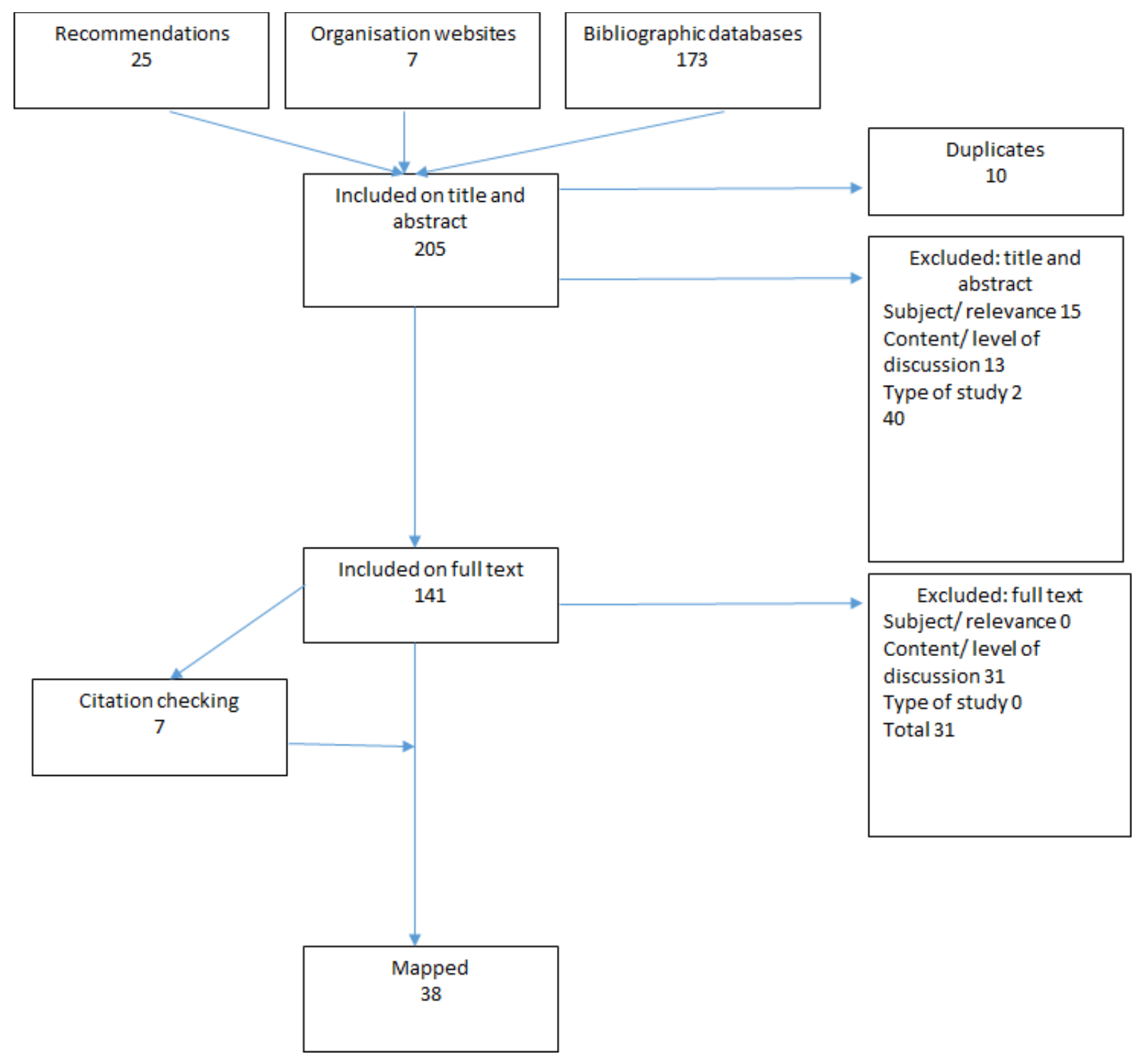

Flow diagram of the systematic review process 


\section{Characterising included studies}

The studies meeting the inclusion criteria after the initial screening were coded according to the following key characteristics:

- Date of publication

- Geographical location

- Author affiliation

- Journal academic discipline

- Keywords

- Name of intervention or project

- Perspective

- Study aims

. Aim of intervention

- Study methods

- Concepts covered

- Components of concepts

- Measures of success

- Implementation issues

\section{Keywords}

Keywords used in journals to help readers navigate their topic of interest and are a helpful way of determining how the authors describe their own work.

Keywords were recorded exactly as described in the journal, then grouped into themes of keywords. The keywords themes indicated interest in:

- The methods used in the study, most of which were modelling and simulation methods

- Energy system management included keywords such as demand response, or implementation strategies.

- Energy generation keywords included smart grid or smart heat networks.

- Energy futures keywords included business model or energy transitions.

. Technology included keywords of Information technology and Web of things,

- Scale and place keywords included local planning, scale and spatiality,

- a small cluster of keywords were about energy justice such as theories of justice, energy justice and sustainability.

There was little discernible pattern within the theme with most keywords coded once i.e. used by one study. 